\title{
QTLs for height: results of a full genome scan in Dutch sibling pairs
}

\author{
Gonneke Willemsen*,1, Dorret I Boomsma ${ }^{1}$, A Leo Beem ${ }^{1}$, Jacqueline M Vink ${ }^{1}$, \\ P Eline Slagboom ${ }^{2}$ and Danielle Posthuma ${ }^{1}$
}

\author{
${ }^{1}$ Department of Biological Psychology, Vrije Universiteit, Amsterdam, The Netherlands; ${ }^{2}$ Sylvius Laboratory, \\ Section Molecular Epidemiology, Leiden Universitary Medical Centre, Leiden, The Netherlands
}

Height is a highly heritable, complex trait. At present, the genes responsible for the variation in height have not yet been identified. This paper summarizes the results of previous linkage studies and presents results of an additional linkage analysis. Using data from the Netherlands Twin Register, a sib-pair-based linkage analysis for adult height was conducted. For 513 sib-pairs from 174 families complete genome scans and adult height were available. The strongest evidence for linkage was found for a region on chromosome 6, near markers D6S1053 and D6S1031 (LOD=2.32). This replicated previous findings in other data sets. LOD scores ranging from 1.53 to 2.04 were found for regions on chromosomes $1,5,8,10$, and 18. The region on chromosome $18(L O D=1.83)$ also corresponded with the results of previous studies. Several chromosomal regions are now implied in the variance in height, but further study is needed to draw definite conclusions with regard to the significance of these regions for adult height. European Journal of Human Genetics (2004) 12, 820-828. doi:10.1038/sj.ejhg.5201229

Published online 11 August 2004

Keywords: heritability; QTL; linkage; sib-pair; twins; adult height; stature

\section{Introduction}

Although many environmental factors may influence body height, in Westernized countries interindividual variation in adult height is to a large extent the result of genetic variation. Heritability estimates for adult height at age 20 years or older range from 0.77 to 0.94 in men and 0.68 to 0.93 in women from seven European Countries and Australia. ${ }^{1}$ These high estimates are in line with those from other studies. ${ }^{2-5}$

With the heritability of adult height well quantified, the next step is to identify specific genes involved in the variation in height. Several linkage and associations studies have been conducted to locate chromosomal regions affecting height. Association studies focus on candidate genes and, with respect to height, have concentrated on an array of growth-related candidate genes. Associations were

*Correspondence: Dr G Willemsen, Department of Biological Psychology, Vrije Universiteit, Van der Boechorststraat 1, Amsterdam 1081 BT, The Netherlands. Tel.: +1 13120 4448787; Fax: + 13120 4448832; E-mail: ahm.willemsen@psy.vu.nl Received 17 December 2003; revised 10 March 2004; accepted 16 April 2004 shown for vitamin $\mathrm{D}$ receptor gene, ${ }^{6} \mathrm{D} 2$ dopamine receptor (DRD2) gene, ${ }^{7-8}$ collagen IA1, ${ }^{9}$ oestrogen receptor gene, ${ }^{10}$ luteinizing hormone beta gene, ${ }^{11}$ and the SHOX gene. ${ }^{12}$ Although association studies have relatively high statistical power to detect quantitative trait loci (QTLs) with small effects, they have recently been criticized as having a higher risk of false positives. ${ }^{13}$ Also, by focusing on genes in known pathways, it is possible to overlook genes involved in currently unknown pathways. Linkage studies are needed to scan the whole genome for chromosomal regions that are related to the trait of interest. However, the statistical power for localizing QTLs in studies using sib-pair designs is much lower. At present, seven papers have been published with results of genomewide scans for adult height, ${ }^{14-20}$ while results from one study pertain to a genome scan in a limited region. ${ }^{21}$ Table 1 presents an overview of the results of these studies. In order to compare the outcomes of the studies, all chromosomal positions were transformed to Kosambi cM for both the Decode and Marshfield map.

LOD scores of 3 and higher were found for regions on six chromosomes: chromosome $3,{ }^{16}$ chromosome $6,{ }^{14,20}$ 
chromosome $7,{ }^{14}$ chromosome $12,{ }^{14}$ chromosome $13,{ }^{14}$ and chromosome $14 .^{19}$ For other positions along the genome LOD scores were below 3. Such lower LOD scores may still be informative and taken as suggestive for linkage, when a consistent pattern emerges for a specific chromosomal region.

The results of some studies in Table 1 seem to provide evidence for linkage for a select number of chromosomal regions. For chromosome 3, results centre around 176.54 and $181.87 \mathrm{cM}$ with additional results at either end of this region, while a promising area at chromosome 5 is located near $138.64-139.33 \mathrm{cM}$. For chromosome 6 , two high LOD scores were found for a region between 154.64 and $159.98 \mathrm{cM}$. Mukhopadhyay et al $^{18}$ reported a peak near this same position, although they did not specify the exact location. For chromosome 7, the region of 155.1$173.71 \mathrm{cM}$ seems a good candidate for QTLs, while for chromosome 9 there seems to be replication of the chromosomal region around $55 \mathrm{cM}$. For chromosome 17 there is a replication for position $103.53 \mathrm{cM}$ and for chromosome 18 there is a replication in the region of 115.89 cM. Lastly, for chromosome 20 two nearby regions seem interesting, around 35 and around $60 \mathrm{cM}$.

Although gradually a pattern is emerging indicating the likely locations of QTLs for adult height, additional replication studies in independent samples are needed to draw more definite conclusions with regard to the relevant chromosomal regions for height. In this paper, we present the linkage results for adult height in a Dutch population of twins and their siblings.

\section{Methods \\ Participants}

In 1991 the Netherlands Twin Register (NTR) started a longitudinal survey study of health and lifestyle. ${ }^{22}$ To this aim, questionnaires were sent out in 1991, 1993, 1995, 1997, and 2000 to adolescent and adult twins and their family members. Twin pairs were asked to participate in all waves, parents were asked to participate in 1991, 1993, and 1995, siblings were included since 1995 and spouses in 2000. Data are currently being collected for a sixth survey.

Body height was obtained from all survey data collected between 1991 and 2000. Height data were only included when height was obtained at age 20 years or older. Most individuals completed questionnaires at more than one survey. Differences in height across the questionnaires were checked and height data were discarded when there was no consistency across questionnaires and differences were larger than $5 \mathrm{~cm}(N=118,1.4 \%)$. In several subsamples, height was also measured in the laboratory during experimental protocols. When measured height was available for age 20 years or older, this was used in the analyses instead of self-reported height $(N=973,12 \%)$. As reported elsewhere, the correlation between self-reported and measured height for this sample is $0.93 .{ }^{1}$ Height at age 20 years or older was available for 5949 twins and 2138 siblings.

Based on questionnaire data on anxiety and depression, a genetic factor score was composed that was used for an extreme discordant and concordant selection for a QTL study of anxious depression (Netherlands Twin family Study of Anxious Depression, see Boomsma et $a l^{23}$ for a detailed description). The participants selected for the QTL study $(n=2.724)$ were asked to provide a buccal swab for DNA isolation. Of the 1962 participants (72\%) who returned a buccal swab, 917 (624 offspring and 293 parents) were genotyped over the entire genome. Participants for whom less than 50\% of the markers were successfully typed were removed from the sample. This resulted in a subsample of 558 offspring and 278 parents from 192 families for whom genotyping was successful.

DNA collection, genotyping, and error checking DNA collection has been described in detail elsewhere. ${ }^{22,24}$ Genotyping was conducted by the Marshfield Laboratory with the $10 \mathrm{cM}$ spaced microsatellite screening set $10^{25}$ with few alternative markers. Pedigrees were checked for Mendelian errors with the program Unknown ${ }^{26}$ and pedigree relationships in the entire sample with the GRR program. ${ }^{27}$ Mendelian errors were removed by assigning missing values to the marker scores if the errors appeared incidental. Likelihoods for recombinations were checked using the Merlin program. ${ }^{28}$ Excessive recombinations were observed for five markers indicating potential problems. Those markers were not included in the final analyses: two markers on chromosome 1 (D1S160-MS48 and D1S1627-ATA25E0); two markers (D11S1985GGAA5C04 and D11S2006-GATA46A12) in a group of five very closely or identically mapped markers on chromosome 11; and one marker on chromosome 20 (D20S159-UT1307). The pseudoautosomal markers on the $\mathrm{X}$-chromosome were not included in the analyses. For all other recombination problems, the data were cleaned using Merlin's procedure for identifying unlikely recombinations, which resulted in the assignment of missing values to genotypes if the likelihood of a recombination was less than 0.025 .

Marker distances were assigned from the Decode map ${ }^{29}$ if available. For markers not mapped by Decode, the original distance provided on the Marshfield website ${ }^{30}$ was transformed by linear interpolation from adjacent markers with known Decode map values.

\section{Identical by descent (IBD) estimation}

If a sibling pair receives the same alleles from a parent in a certain region of the genome, the pair is said to share the parent's alleles in that region IBD. Since offspring receive their alleles from two parents, a sib-pair can share 0,1 . or 2 
Table 1 Overview of the results of previous genomewide scans for height

\begin{tabular}{|c|c|c|c|c|c|c|}
\hline Chromosome position & Peak marker(s) & cM according to Decode & cM according to Marshfield & $L O D$ & Population & $N$ ss/N fam \\
\hline $1 \mathrm{p} 35.3$ & D1S1622 & 48.69 & 56.74 & 1.27 & Combination of populations ${ }^{19}$ & $6752 / 2508$ \\
\hline $1 \mathrm{p} 31.1$ & D1S1665 & 99.62 & 102.02 & 1.01 & Sweden ${ }^{14}$ & $683 / 179$ \\
\hline $1 \mathrm{p} 21.1$ & D1S1631 & 125.75 & 136.88 & 2.25 & Genoa African American ${ }^{19}$ & $\mathrm{nr}$ \\
\hline $1 \mathrm{q} 24.2$ & D1S210 & 174.09 & 188.85 & 1.35 & Botnia $^{14}$ & $379 / 58$ \\
\hline $2 \mathrm{p} 13.2$ & D2S1394 & nd & 90.82 & 1.27 & Combination of populations ${ }^{19}$ & $6752 / 2508$ \\
\hline 2 na-p21 & D2S2305-D2S2306 & $65.75-66.84$ & $61.66-63.41$ & 1.56 & Finland 17 & $580 / 247$ \\
\hline $2 q 11.2$ & D2S113 & nd & 111.21 & 2.23 & Botnia $^{14}$ & $379 / 58$ \\
\hline $2 q 31.3$ & D2S364-D2S116 & $187.67-198.66$ & $186.21-198.65$ & 1.29 & Botnia $^{14}$ & $379 / 58$ \\
\hline $2 q 37.1$ & D2S206 & 240.03 & 240.79 & 1.51 & United Kingdom $^{16}$ & 1136 sibpairs \\
\hline $3 p 26.1$ & D3S1297-D3S1304 & nd-19.61 & $8.31-22.33$ & 3.17 & United Kingdom $^{16}$ & 1136 sibpairs \\
\hline $3 \mathrm{p} 14.2$ & D3S1766 & 79.08 & 78.64 & 2.31 & Finland $^{14}$ & $702 / 183$ \\
\hline $3 q 23$ & D3S1764 & 145.53 & 152.62 & 2.03 & Combination of populations ${ }^{19}$ & $6752 / 2508$ \\
\hline $3 q 26.1$ & D3S1763 & 168.52 & 176.54 & 2.06 & GENOA European American ${ }^{19}$ & $\mathrm{nr}$ \\
\hline 3na & D3S3053 & nd & 181.87 & 1.49 & Botnia $^{14}$ & $379 / 58$ \\
\hline $3 q 28$ & D3S2398 & 203.31 & 209.41 & 1.19 & Saguenay-Lac-St.Jean ${ }^{14}$ & $347 / 6$ \\
\hline $4 \mathrm{p} 16.3$ & D4S1614 & nd & 4.74 & 1.30 & Botnia $^{14}$ & $379 / 58$ \\
\hline 4p15.3 & D4S403 & 26.71 & 25.9 & 1.26 & Saguenay-Lac-St.Jean ${ }^{14}$ & $347 / 6$ \\
\hline 4p15.2 & D4S391 & 47.33 & 43.59 & 1.58 & Nebraska 15 & $671 / 53$ \\
\hline $4 \mathrm{q} 25$ & D4S1564 & nd & 112.63 & 2.28 & Botnia $^{14}$ & $379 / 58$ \\
\hline $4 q 35.1$ & D4S1540 & nd & 199.93 & 1.73 & Finland ${ }^{14}$ & $702 / 183$ \\
\hline $4 \mathrm{q} 35.2$ & D4S3051-D4S426 & $200.02-202.69$ & $203.77-206.98$ & 1.89 & Botnia $^{14}$ & $379 / 58$ \\
\hline 5 na & GATA67D03 & 75.18 & 69.23 & 1.75 & Sweden ${ }^{14}$ & $683 / 179$ \\
\hline $5 q 23.1$ & D5S1505 & 125.35 & 129.83 & 1.08 & Combination of populations ${ }^{19}$ & $6752 / 2508$ \\
\hline $5 q 31.1$ & D5S2115 & 136.75 & 138.64 & 1.89 & Nebraska ${ }^{15}$ & $671 / 53$ \\
\hline $5 q 31.1$ & D5S816 & 138.04 & 139.33 & 2.26 & HyperGen European American ${ }^{19}$ & $\mathrm{nr}$ \\
\hline $5 q 31.1$ & D5S816 & 138.04 & 139.33 & 1.48 & SAPPHIRE Asian 19 & $\mathrm{nr}$ \\
\hline $6 \mathrm{p} 25.3$ & D6S942 & 0 & 0 & 1.42 & Finland $^{14}$ & $580 / 247$ \\
\hline $6 \mathrm{p} 25.1$ & D6S1574 & 15.18 & 9.18 & 1.08 & Sweden ${ }^{14}$ & $683 / 179$ \\
\hline $6 q 12$ & D6S1053 & nd & 80.45 & 2.66 & GENOA European American ${ }^{19}$ & $\mathrm{nr}$ \\
\hline $6 q 16.3$ & D6S1021 & 107.15 & 112.2 & 1.82 & Botnia $^{14}$ & $379 / 58$ \\
\hline 6 na & D6S2436 & 161.27 & 154.64 & 3.06 & Netherlands ${ }^{20}$ & $1184 / 200$ \\
\hline $6 q 25.3$ & D6S1007 & nd & 159.98 & 3.85 & Botnia ${ }^{14}$ & $379 / 58$ \\
\hline $6 q 27$ & $\mathrm{nr}$ & $\mathrm{nr}$ & $\mathrm{nr}$ & 1.10 & Framingham Heart Study ${ }^{18}$ & $1687 / 335$ \\
\hline $7 q 21.11$ & D7S669-D7S630 & $89.39-99.93$ & $90.42-98.44$ & 2.26 & United Kingdom ${ }^{16}$ & 1136 sibpairs \\
\hline $7 q 31.32$ & D7S1517-D7S2486 & $126.77-n d$ & $126.75-127.82$ & 1.30 & Finland ${ }^{17}$ & $580 / 247$ \\
\hline $7 q 35$ & D7S2195(GATA150C06) & nd & 155.1 & 3.40 & Sweden ${ }^{14}$ & $683 / 179$ \\
\hline $7 \mathrm{q} 36.1$ & D7S2439-D7S1523 & nd-nd & $163.74-165.18$ & 2.91 & Finland $^{17}$ & $580 / 247$ \\
\hline 7qtel & D7S3058 & nd & 173.71 & 2.46 & Combination of populations ${ }^{19}$ & $6752 / 2508$ \\
\hline $8 p 23.1$ & D8S277 & 15.23 & 8.34 & 1.26 & Combination of populations ${ }^{19}$ & $6752 / 2508$ \\
\hline $8 \mathrm{p} 23.1$ & D8S550 & nd & 21.33 & 1.93 & Nebraska $^{15}$ & $671 / 53$ \\
\hline $8 \mathrm{p} 21.2$ & D8S1752 & 40.75 & 46.24 & 1.31 & Finland $^{14}$ & $702 / 183$ \\
\hline $8 q 24.2-q 24.3$ & D8S1100-D8S373 & $148.81-164.47$ & $154.02-164.47$ & 2.52 & Finland $^{14}$ & $702 / 183$ \\
\hline
\end{tabular}




\begin{tabular}{|c|c|c|c|c|c|c|}
\hline 9p21.1 & D9S1868 & 53.04 & 51.81 & 2.01 & Botnia $^{14}$ & $379 / 58$ \\
\hline $9 \mathrm{p} 21.1$ & D9S319 & 53.19 & 54.5 & 1.64 & Framingham Heart Study-men ${ }^{18}$ & \\
\hline $9 q 21.1$ & D9S301 & 66.99 & 66.32 & 2.09 & Netherlands 20 & $1184 / 200$ \\
\hline $9 q 34.2-q 34.3$ & D9S1818-D9S1826 & $150.42-157.73$ & $150.92-159.61$ & 2.61 & Finland $^{17}$ & $580 / 247$ \\
\hline $10 q 21$ & GATA121A08 & nd & 88.41 & 1.09 & Framingham Heart Study-women ${ }^{18}$ & $\mathrm{nr}$ \\
\hline $10 \mathrm{q} 23.1$ & D10S1686 & nd & 105.04 & 1.93 & United Kingdom $^{16}$ & 1136 sibpairs \\
\hline $11 \mathrm{p} 15.5$ & D11S1984 & 0 & 2.11 & 1.47 & Botnia $^{14}$ & $379 / 58$ \\
\hline $11 \mathrm{p} 15.4$ & D11S2362-D11S1999 & $7.27-17.05$ & $8.9-17.19$ & 2.57 & Sweden $^{14}$ & $683 / 179$ \\
\hline $11 \mathrm{q} 13.2$ & D11S1337 & 72.41 & 68.55 & 1.84 & Botnia $^{14}$ & $379 / 58$ \\
\hline $12 \mathrm{p} 13.3$ & D12S341 & nd & 0.62 & 2.07 & Finland $^{14}$ & $702 / 183$ \\
\hline $12 q 13.1$ & D12S1090-D12S398 & nd-67.42 & $56.38-68.16$ & 3.35 & Finland $^{14}$ & $702 / 183$ \\
\hline $12 q 15$ & D12S375 & 84.37 & 80.52 & 1.86 & Netherlands ${ }^{20}$ & $1184 / 200$ \\
\hline $13 q 12.1-q 13.1$ & D13S221-GGAA29H03 & $16.26-31.76$ & $12.91-25.8$ & 1.01 & Finland $^{14}$ & 702/183 \\
\hline $13 q 33.1$ & D13S779-D13S797 & $95.76-105.22$ & 82.93-na & 3.56 & Finland $^{14}$ & $702 / 183$ \\
\hline $14 q 21.1-q 21.2$ & D14S286-D14S288 & nd- 44 & $45.12-47.51$ & 1.67 & Finland $^{17}$ & $580 / 247$ \\
\hline $14 q 23.1$ & D14S592 & 60.5 & 66.81 & 3.67 & GENOA European American ${ }^{19}$ & $\mathrm{nr}$ \\
\hline $14 q 23.1$ & D14S592 & 60.5 & 66.81 & 1.60 & SAPPHIRE Asian ${ }^{19}$ & $\mathrm{nr}$ \\
\hline $15 q 12$ & D15S1002 & 15.05 & 14.58 & 1.90 & United Kingdom $^{16}$ & 1136 sibpairs \\
\hline $15 q 26.2$ & D15816 & 110.93 & 100.59 & 1.33 & Finland $^{14}$ & $702 / 183$ \\
\hline 17p12 & D17S122 & nd & 41.12 & 1.35 & Saguenay-Lac-St.Jean ${ }^{14}$ & $347 / 6$ \\
\hline $17 q 21.3$ & D17S958 & 74.32 & 66.85 & 2.69 & Botnia $^{14}$ & $379 / 58$ \\
\hline $17 q 25.1$ & D17S785 & 115.34 & 103.53 & 1.67 & Nebraska $^{15}$ & $671 / 53$ \\
\hline $17 q 25.1-25.3$ & D17S785-D17S784 & $115.34-129.62$ & $103.53-116.86$ & 1.24 & United Kingdom ${ }^{16}$ & 1136 sibpairs \\
\hline 18q21.1-na & D18S473-GATA06 & nd-nd & $71.32-74.93$ & 1.70 & Finland $^{17}$ & $580 / 247$ \\
\hline $18 q 22.1$ & D18S1364 & nd & 99.04 & 1.38 & Framingham Heart Study ${ }^{18}$ & $1687 / 335$ \\
\hline 18q22.3-na & D18S541-D18S1121 & $100.54-108.67$ & $106.81-115.89$ & 1.58 & Botnia $^{14}$ & $379 / 58$ \\
\hline 18na & D18S1121 & 108.67 & 115.89 & 1.77 & Finland $^{14}$ & $702 / 183$ \\
\hline $19 p 13.3$ & D19S878-D19S247 & nd-nd & $6.57-9.84$ & 1.25 & Sweden ${ }^{14}$ & $683 / 179$ \\
\hline 19p13.2-p13.1 & D19S221-D19S226 & $32.39-36.35$ & $36.22-42.28$ & 1.56 & United Kingdom ${ }^{16}$ & 1136 \\
\hline $19 \mathrm{p} 12-11$ & D19S1037 & 44.14 & 47.67 & 1.36 & Framingham Heart Study-men ${ }^{18}$ & \\
\hline $20 \mathrm{p} 12.1$ & D20S604 & 35.78 & 32.94 & 1.77 & Combination of populations ${ }^{19}$ & $6752 / 2508$ \\
\hline $20 \mathrm{p} 12.1$ & D20S98-D20S66 & $38.23-40.76$ & $34.22-37.65$ & $\mathrm{nr}$ & Pima Indians ${ }^{21}$ & $924 / 226-568$ \\
\hline $20 q 13.1$ & D20S96 & 66.55 & 58.48 & 2.51 & Botnia $^{14}$ & $379 / 58$ \\
\hline $20 q 13.1$ & D20S119-D20S178 & $69.4-73.83$ & $61.77-66.16$ & 1.29 & United Kingdom $^{16}$ & 1136 sibpairs \\
\hline 21 pter & D21S1432 & 8.54 & 2.99 & 1.35 & Framingham Heart Study-women ${ }^{18}$ & $\mathrm{nr}$ \\
\hline $21 \mathrm{q} 21.1$ & D21S1437 & nd & 13.05 & 1.04 & Saguenay-Lac-St.Jean ${ }^{14}$ & $347 / 6$ \\
\hline 22 centr & D22S420 & 2.96 & 4.06 & 1.95 & Sweden $^{14}$ & $683 / 179$ \\
\hline $22 q 11.2$ & D22S345 & 18.8 & 19.32 & 1.10 & Framingham Heart Study ${ }^{18}$ & $1687 / 335$ \\
\hline 22na & D22S281 & 38.55 & 31.84 & 1.66 & Botnia $^{14}$ & $379 / 58$ \\
\hline $22 q 12-13$ & D22S683 & nd & 36.22 & 1.12 & Framingham Heart Study-men ${ }^{18}$ & $\mathrm{nr}$ \\
\hline 22 na & $\mathrm{D} 22 \mathrm{~S} 282$ & 38.55 & 131.84 & 1.10 & Finland $^{-4}$ & $702 / 183$ \\
\hline Xp22.2 & DXS1060 & 12.71 & 15.12 & 1.95 & Nebraska $^{15}$ & $671 / 53$ \\
\hline Xp24 & DXS1001 & 120.35 & 75.79 & 1.91 & Nebraska $^{15}$ & $671 / 53$ \\
\hline
\end{tabular}

Notes: LOD $\geq 1.5$ in Deng et $a l_{;}^{15}$ LOD $\geq 1.18$ in Wiltshire et al; LOD $>1.5$ in Xu et $a l^{20}{ }^{2}$ Perola et $a l^{17}$ provided Marshfield positions, markers for these positions have been obtained using the Ensemble database. $\mathrm{na}=$ location unavailable in Ensemble database; $\mathrm{nd}=$ no Decode location available; $\mathrm{nr}=$ not reported. 
alleles IBD. The IBD status of a pair is usually estimated for a number of markers with (approximately) known location along the genome and is then used as a measure of genetic similarity. The IBD status at a marker is informative for the IBD status at any other locus (eg a disease or trait locus) along the chromosome as long as the population recombination fraction between the marker and the locus is less than 0.5. In that case, the IBD status at the marker and the locus are correlated in the population, and hence similarity at the marker is informative for similarity at the locus. IBD status is not always unambiguously known and has to be estimated using the specific allele pattern across chromosomes of two or more siblings and parents. The estimate of the proportion of alleles shared IBD is referred to as $\hat{\pi}$, and is obtained as: $\hat{\pi}_{i j k}=0 \times p_{(\mathrm{IBD}=0)_{i j k}}+\frac{1}{2} \times p_{(\mathrm{IBD}=1)_{i j k}}+$ $1 \times p_{(\mathrm{IBD}=2)_{i j k}}$, where $\hat{\pi}_{i j k}$ is the estimated proportion of alleles shared IBD between sib $j$ and $k$ for the $i$ th family, and $p_{(\mathrm{IBD}=0)_{i j k^{\prime}}} p_{(\mathrm{IBD}=1)_{i j k}}$ and $p_{(\mathrm{IBD}=2)_{i j k}}$ are the probabilities that sib $j$ and $k$ share 0,1 , or 2 alleles, respectively, conditional on the marker information. The probabilities of sharing 0,1 , or 2 alleles IBD at every $7.544 \mathrm{cM}$ (Haldane map) over the genome were estimated with the program Merlin ${ }^{28}$ (autosomal chromosomes) or Merlin-in-X $\left(\mathrm{MINX}^{28}\right)$ for the X-chromosome.

\section{Genetic model fitting}

Genotypic data as well as adult height at 20 years or older were available for 477 offspring from 174 families, forming 513 sib-pairs. Although this does not provide information for linkage, phenotypic data from participants for whom no genotypic data were available were simultaneously analysed to obtain accurate estimates of the effects of covariates and background genetic influences. The total (typed + untyped) sample consisted of 8087 offspring from 3617 families, with an average of 2.2 offspring per family. As an additional check analyses were run with and without the untyped participants.

We included effects of sex and birth cohort on body height. The latter was included to take into account the secular increase in body height in the Dutch population; adult height increases with more than $1 \mathrm{~cm}$ per decade. ${ }^{31}$

In a previous study, it was demonstrated that variation in body height in the Dutch population consists of additive genetic variation (89\% in males and 90\% in females) and nonshared environmental variation. ${ }^{1}$ Variation in body height was decomposed into variation due to a QTL $\left(\sigma_{\mathrm{q}}^{2}\right)$, due to additive influences $\left(\sigma_{\mathrm{a}}^{2}\right)$, and due to nonshared environmental influences $\left(\sigma_{\mathrm{e}}^{2}\right)$, using structural equation modelling as implemented in $\mathrm{Mx}{ }^{32}$ The X-chromosome was analysed using option --vc in MINX. ${ }^{28}$ Estimates of the variance component associated with a putative QTL were obtained by using the $\hat{\pi}$ approach, in which the covariance due to the marker or trait locus for a sib-pair is modelled as a function of the estimated proportion of alleles shared IBD. As stated earlier, height data from genotyped and untyped individuals were simultaneously modelled to allow more accurate estimation of the background genetic variance, the effect of sex on body height, and the cohort effect. For the untyped pairs, $\sigma_{\mathrm{a}}^{2}$ consisted of $\left(\sigma_{\mathrm{a}}^{2}+\sigma_{\mathrm{q}}^{2}\right)$. The general variance-covariance matrix for pair $j, k$ of the $i$ th family $\left(\Omega_{i j k}\right)$ is given by

$$
\Omega_{i j k}=\begin{array}{ll}
\sigma_{a}^{2}+\sigma_{q}^{2}+\sigma_{e}^{2} & \text { if } j=k \\
\rho \sigma_{a}^{2}+\hat{\pi}_{i j k} \sigma_{q}^{2} & \text { if } j \neq k
\end{array}
$$

Here $\sigma_{\mathrm{a}}^{2}, \sigma_{\mathrm{q}}^{2}$, and $\sigma_{\mathrm{e}}^{2}$ denote the background additive genetic, QTL, and environmental variances, with $\rho=1$ for MZ twins and $\rho=\frac{1}{2}$ for DZ twins. Significance of genetic variation due to the QTL was evaluated by the likelihood ratio test, from which the LOD score can be calculated by dividing the test statistic $\chi^{2}$ by $2 \ln 10(\sim 4.6) .{ }^{33}$

\section{Results}

Table 2 shows the descriptives for the total sample of offspring with adult height $(N=8087)$ and the genotyped sample of offspring with adult height $(N=477)$. Body height was normally distributed and comparable across the total sample and the genotyped sample (Table 2). This result, taken together with low correlations between body height and the anxious depression factor scores $(-0.02$ and -0.03), indicates that the genotyped subsample can be considered to be a random selection of the total sample for body height. Males were on average $13.18 \mathrm{~cm}$ taller than females (95\% confidence interval (CI): 12.91-13.45, $P<0.001)$. The cohort effect indicated that body height in the Dutch population shows an annual increase of $0.13 \mathrm{~cm}$ (95\% CI: $0.12-0.14, P<0.001)$.

Figure 1 shows the results of the whole-genome scan. The highest peak (LOD score of 2.32) was found on chromosome 6 at approximately 84.38 Kosambi cM between markers D6S1053 and D6S1031. Six other peaks with LOD scores ranging from 1.53 to 2.04 were found on chromosomes $1,5,8,10$, and 18 . These results are outlined in Table 3 and shown in Figure 2.

\section{Discussion}

As a highly heritable, complex trait height presents a prime candidate for identifying the responsible genes by means of linkage analysis. The current article presented the results of a linkage analysis for adult height using data from Dutch twins and siblings. The highest LOD score in our study was obtained for a region on chromosome 6 , near the markers D6S1053 and D6S1031 (LOD = 2.32), while LOD scores of at least 1.53 were shown for regions on chromosomes 1,5 , 8,10 , and 18 . It is important that results are replicated in other samples before drawing conclusions about the significance of a chromosomal region. In the current article, we reviewed the results of previous studies and indicated some chromosomal regions for which there was 
Table 2 Number of participants $(N)$, mean age at 1-1-2003 (SD) and mean height in $\mathrm{cm}(S D)$ for the total population and the genotyped subsample

\begin{tabular}{lcccccc}
\hline & \multicolumn{3}{c}{ Total sample } & \multicolumn{3}{c}{ Genotyped subsample } \\
& $N$ & Age at 1-1-2003 & Height in cm & $N$ & Age at 1-1-2003 & Height in cm \\
\hline Males & 3206 & $33.94(10.07)$ & $182.87(7.03)$ & 197 & $36.99(11.68)$ & $182.70(6.67)$ \\
Females & 4884 & $34.19(10.31)$ & $169.52(6.51)$ & 280 & $36.78(12.07)$ & $169.97(6.31)$ \\
Total & 8087 & $34.09(10.21)$ & $174.81(9.37)$ & 477 & $36.86(11.90)$ & $175.23(9.00)$ \\
\hline
\end{tabular}

Note: The total sample consisted of $2700 \mathrm{MZ}$ members, $3249 \mathrm{DZ}$ twin members, and 2138 nontwin siblings from 3617 families. The genotyped sample consisted of 477 subjects from 174 families, generating 513 sib-pairs.

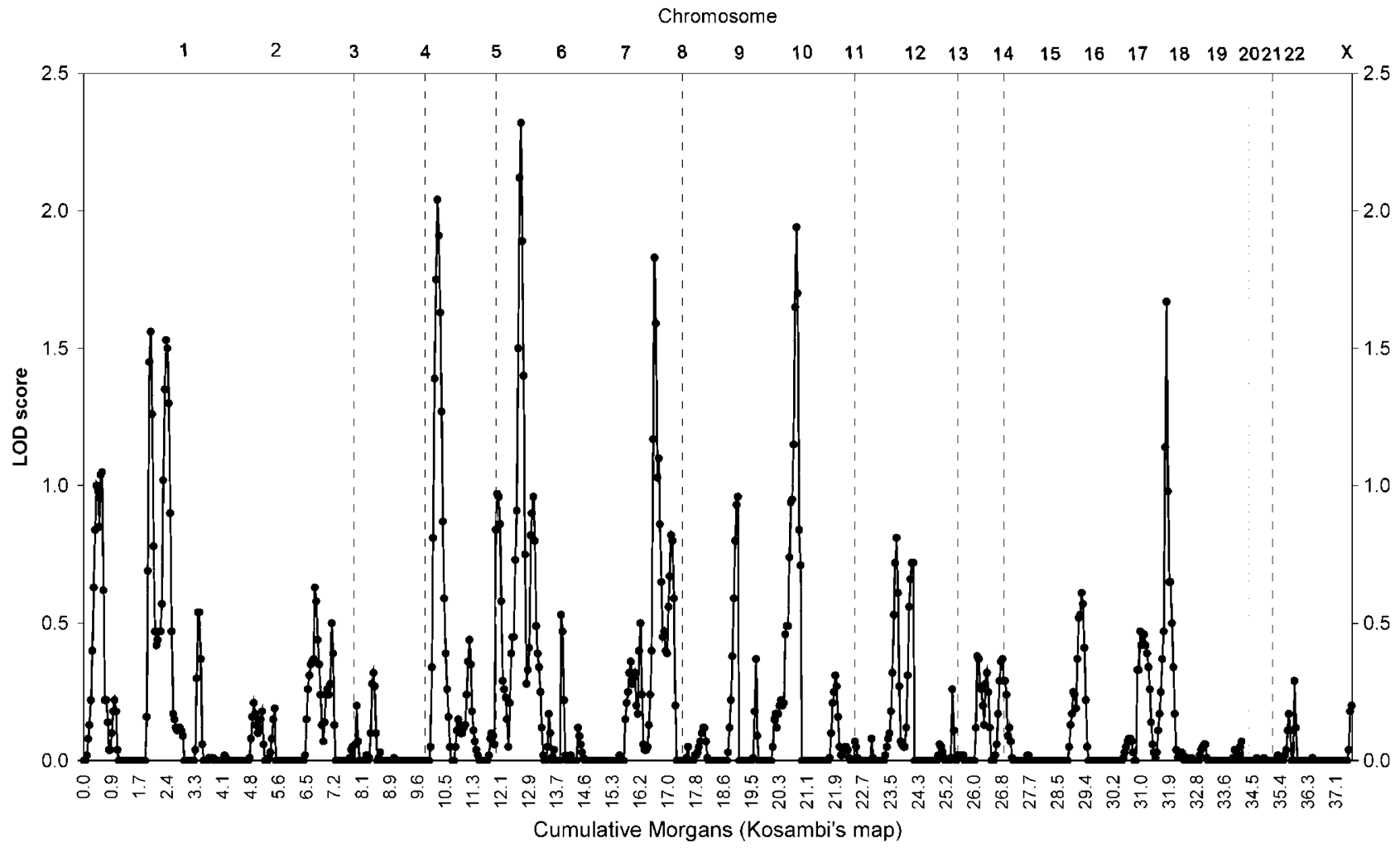

Figure 1 Whole-genome scan for height.

consistent evidence for linkage. Our result for chromosome 6 was a replication of the result reported by Wu et al ${ }^{19}$ for the GENOA European American sample, where a LOD score of 2.66 was found for the same region. Two other studies, including another Dutch population, also found evidence for linkage on chromosome 6, although for another region than in the present study. ${ }^{14,20}$ However, estimates for QTL locations obtained for complex traits through linkage analyses may be many centimorgans from the true locus. Roberts et $a l^{34}$ used simulations to show that with a sample size of 200 families CIs around the peak location may cover $30-100 \mathrm{cM}$. With a sample size of 800 families, the $95 \%$ CIs around the peak location may still cover $15-35 \mathrm{cM}$. Even when specific QTLs on a chromosome may not be replicated, repeated linkage for nearby areas on a chromosome may indicate a significance of that region for the trait of interest. In this case, our current results and that of previous studies seem to warrant more detailed study of the regions identified on chromosome 6 . This is further supported by the fact that the oestrogen receptor alpha, which has been associated with height, ${ }^{10}$ is located within the same region. A replication was also shown for our peak at $98.3 \mathrm{cM}$ on chromosome 18; Hirschhorn et al ${ }^{14}$ also 
Table 3 Linkage results of the sib-pair based linkage for height

\begin{tabular}{|c|c|c|c|c|c|}
\hline Chromosome & Chromosome region & Peak markers & Decode & Marshfield & $L O D$ \\
\hline 1 & $q 31.3-q 32.2$ & D1S1660-D1S2782 & $194.98-209.84$ & $212.44-222.84$ & 1.56 \\
\hline 1 & $\mathrm{q} 42.3-\mathrm{q} 42.3$ & D1S3462-D1S235 & $235.37-244.4$ & $247.23-254.64$ & 1.53 \\
\hline 5 & p14.3-p13.3 & D5S2845-D5S1470 & nd-53.87 & $36.25-45.34$ & 2.0 \\
\hline 6 & $q 12-q 14.1$ & D6S1053-D6S1031 & nd-89.14 & $80.45-88.63$ & 2.32 \\
\hline 8 & $q 21.11-q 22.2$ & D8S234-GAAT1A4 & nd-104.28 & $94.08-110.2$ & 1.83 \\
\hline 10 & na-q26.3 & D10S1248-D10S212 & nd-177.19 & $165.27-170.94$ & 1.9 \\
\hline 18 & na-qq22.3 & GATA2E08-ATA82B02 & nd-98.83 & $99.04-106.81$ & 1.6 \\
\hline
\end{tabular}

$\mathrm{na}=$ location unavailable in Ensembl; $\mathrm{nd}=$ no Decode location available.

CHROMOSOME 1

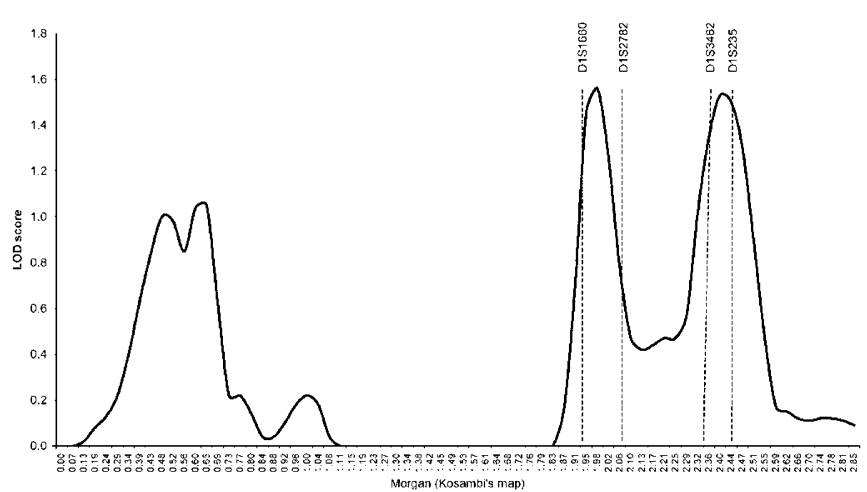

Morgan (Kosambis map)

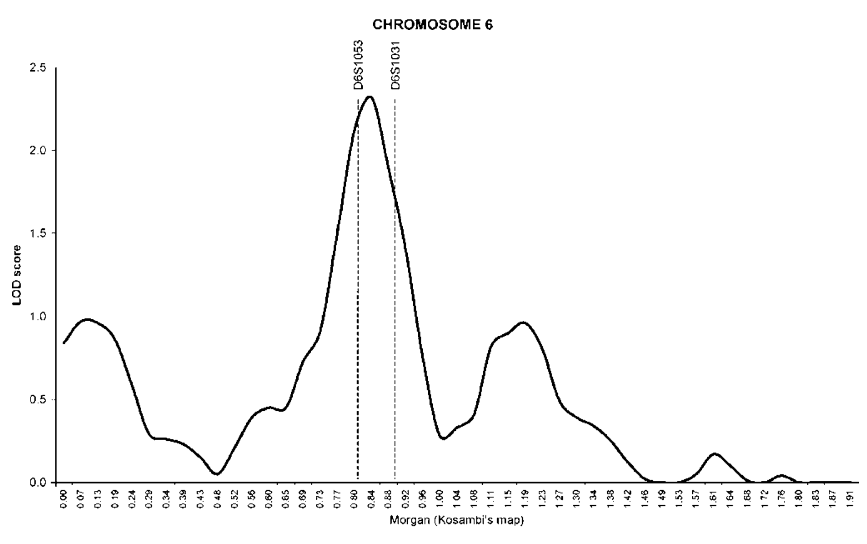

CHROMOSOME 10

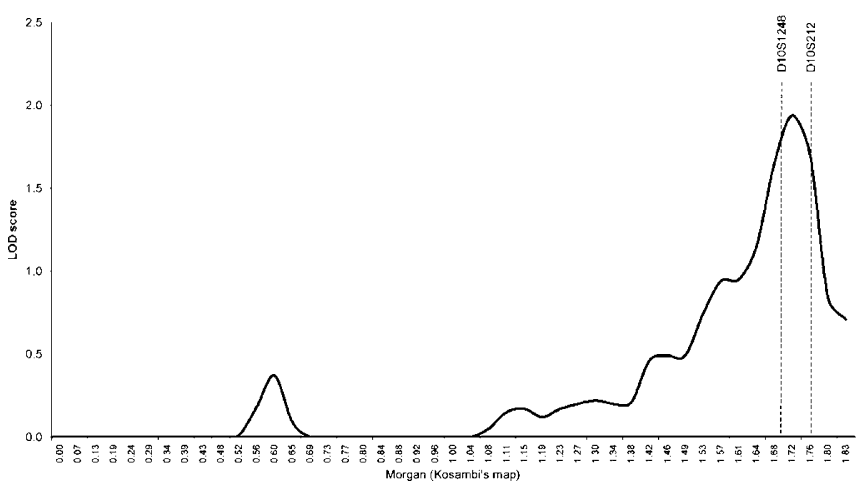

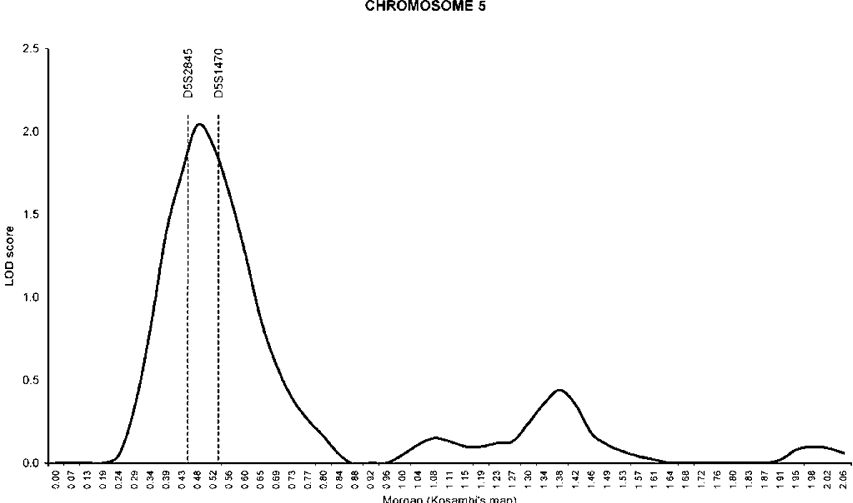

CHROMOSOME 8

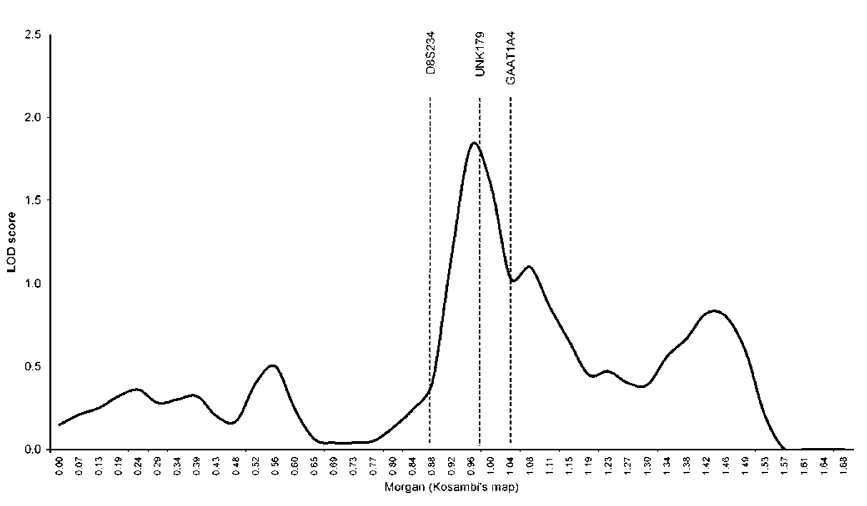

CHROMOSOME 18

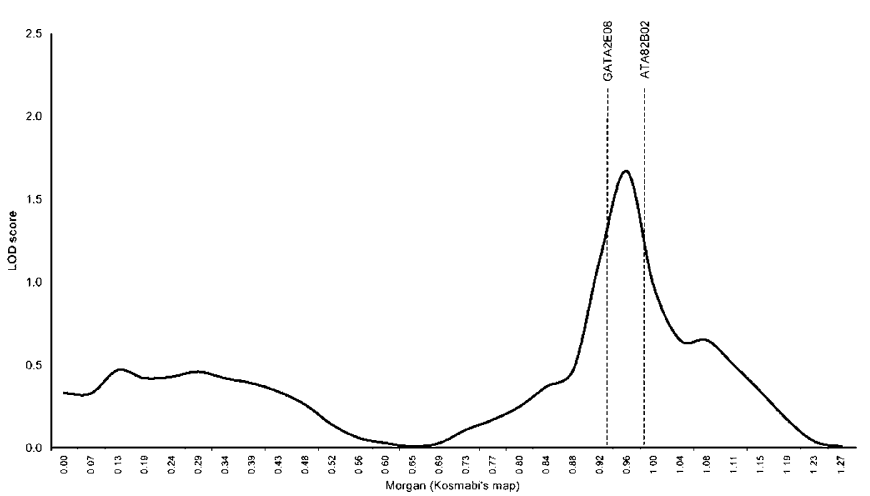

Figure 2 Linkage results for chromosomes showing LOD scores above 1.5 for height. 
reported increased LOD scores for the region of 106.81 and 115.89 at chromosome 18 in the Botnia and the Finland population, while Mukhopadhyay et al ${ }^{18}$ reported an increased LOD score at $99.04 \mathrm{cM}$.

Specific population characteristics may decrease the generalizability of results to other populations. A geneenvironment interaction may increase the effect of a particular gene for height and may limit the replication of effects. However, most populations studied have been Western populations and lifestyle factors may therefore be fairly similar across the populations. A further complication may arise because different analysis packages may result in different LOD scores for the same regions. This was recently demonstrated by Mukhopadhyay et al, ${ }^{18}$ further emphasizing the need to include lower LOD scores when comparing study results. Combining the results of studies may prove critical to the identification of chromosomal regions important for height: ${ }^{35}$ no single study can be expected to localize all genes involved in height but a meta-analysis may indicate which chromosomal regions with small but consistent effects are worth further investigation. The small effects for a variety of genes would suggest height to be a polygenic trait. This would be in contrast to the results of a segregation analysis in which height was predicted by a putative major gene, explaining $37-53 \%$ of the variance. ${ }^{36} \mathrm{~A}$ more recent analysis ${ }^{20}$ also found that a model that included a major recessive gene and residual polygenic effect (mixed-recessive model) best fitted the height data. However, the difference between the mixed-recessive model and the polygenic model was very small and both models fitted the data equally well when spouse correlations were included in the model. Considering height as a polygenic trait, it may not be surprising that the different linkage analyses show a diverse pattern with many genes having small effects.

In conclusion, the present study replicated previous findings for possible QTLs on chromosomes 6 and 18 . However, additional linkage studies are needed to draw more definite conclusions about the relevance of these regions for determining adult height.

\section{Acknowledgements}

This work was supported by the Netherlands Organization for Scientific Research (NWO 904-61-090) and the GenomEUtwin project supported by the European Union Contract No. QLG2-CT-200201254. Genotyping was carried out by the Centre for Medical Genetics in Marshfield ( http://research.marshfieldclinic.org/genetics/). We would like to thank E Suchiman and N Lakenberg for DNA isolation and JJ Hottenga for his comments on the manuscript.

\section{References}

1 Silventoinen K, Sammalisto S, Perola M et al: Heritability of adult body height: a comparative study of twin cohorts in eight countries. Twin Res 2003; 6: 399-408.

2 Carmichael CM, McGue M: A cross-sectional examination of height, weight, and body mass index in adult twins. J Gerontol $A$ Biol Sci Med Sci 1995; 50: B237-B244.
3 Preece MA: The genetic contribution to stature. Horm Res 1996; 45 (Suppl 2): 56-58.

4 Philips K, Metheny A: Quantitative genetic analysis of longitudinal trends in height: preliminary results from the Louisville Twin Study. Acta Genet Med Gemellol 1990; 39: 143-163.

5 Silventoinen K, Kaprio J, Lahelma E, Viken RJ, Rose RJ: Sex differences in genetic and environmental factors contributing to body-height. Twin Res 2001; 4: 25-29.

6 Minamitani K, Takahashi Y, Minagawa M, Yasuda T, Niimi H: Difference in height associated with a translation start site polymorphism in the vitamin D receptor gene. Pediatr Res 1998; 44: $628-632$

7 Miyake H, Nagashima K, Onigata K, Nagashima T, Takano Y, Morikawa A: Allelic variations of the D2 dopamine receptor gene in children with idiopathic short stature. J Hum Genet 1999; 44: 26-29.

8 Arinami T, Iijima Y, Yamakawa-Kobayashi $\mathrm{K}$ et al: Supportive evidence for contribution of the dopamine D2 receptor gene to heritability of stature: linkage and association studies. Ann Hum Genet 1999; 63 (Part 2): 147-151.

9 Garnero P, Borel O, Grant SF, Ralston SH, Delmas PD: Collagen Ialpha1 Sp1 polymorphism, bone mass, and bone turnover in healthy French premenopausal women: the OFELY study. J Bone Miner Res 1998; 13: 813-817.

10 Lorentzon M, Lorentzon R, Backstrom T, Nordstrom P: Estrogen receptor gene polymorphism, but not estradiol levels, is related to bone density in healthy adolescent boys: a cross-sectional and longitudinal study. J Clin Endocrinol Metab 1999; 84: 4597-4601.

11 Raivio T, Huhtaniemi I, Anttila R et al: The role of luteinizing hormone-beta gene polymorphism in the onset and progression of puberty in healthy boys. J Clin Endocrinol Metab 1996; 81: $3278-3282$

12 Rao E, Weiss B, Fukami $\mathrm{M}$ et al: Pseudoautosomal deletions encompassing a novel homeobox gene cause growth failure in idiopathic short stature and Turner syndrome. Nat Genet 1997; 16: $54-63$.

13 In search of genetic precision. Lancet 2003; 361: 357.

14 Hirschhorn JN, Lindgren CM, Daly MJ et al: Genomewide linkage analysis of stature in multiple populations reveals several regions with evidence of linkage to adult height. Am J Hum Genet 2001; 69: 106-116.

15 Deng HW, Xu FH, Liu YZ et al: A whole-genome linkage scan suggests several genomic regions potentially containing QTLs underlying the variation of stature. Am J Med Genet 2002; 113: $29-39$.

16 Wiltshire S, Frayling TM, Hattersley AT et al: Evidence for linkage of stature to chromosome 3 p26 in a large UK. Family data set ascertained for type 2 diabetes. Am J Hum Genet 2002; 70 : 543-546.

17 Perola M, Ohman M, Hiekkalinna T et al: Quantitative-trait-locus analysis of body-mass index and of stature, by combined analysis of genome scans of five Finnish study groups. Am J Hum Genet 2001; 69: 117-123.

18 Mukhopadhyay N, Finegold DN, Larson MG, Cupples LA, Myers RH, Weeks DEA: Genome-wide scan for loci affecting normal adult height in the Framingham Heart Study. Hum Hered 2003; 55: 191-201.

$19 \mathrm{Wu} \mathrm{X}$, Cooper RS, Boerwinkle E et al: Combined analysis of genomewide scans for adult height: results from the NHLBI Family Blood Pressure Program. Eur J Hum Genet 2003; 11: 271-274.

$20 \mathrm{Xu} \mathrm{J}$, Bleecker ER, Jongepier $\mathrm{H}$ et al: Major recessive gene(s) with considerable residual polygenic effect regulating adult height: confirmation of genomewide scan results for chromosomes 6, 9 , and 12. Am J Hum Genet 2002; 71: 646-650.

21 Thompson DB, Ossowski V, Janssen RC, Knowler WC, Bogardus $\mathrm{C}$ : Linkage between stature and a region on chromosome 20 and analysis of a candidate gene, bone morphogenetic protein 2. Am J Med Genet 1995; 59: 495-500. 
22 Boomsma DI, Vink JM, van Beijsterveldt TC et al: Netherlands Twin Register: a focus on longitudinal research. Twin Res 2002; 5: 401-406.

23 Boomsma DI, Beem AL, van den BM et al: Netherlands twin family study of anxious depression (NETSAD). Twin Res 2000; 3: $323-334$

24 Meulenbelt I, Droog S, Trommelen GJ, Boomsma DI, Slagboom PE: High-yield noninvasive human genomic DNA isolation method for genetic studies in geographically dispersed families and populations. Am J Hum Genet 1995; 57: 1252-1254.

25 Yuan B, Vaske D, Weber JL, Beck J, Sheffield VC: Improved set of short-tandem-repeat polymorphisms for screening the human genome. Am J Hum Genet 1997; 60: 459-460.

26 Schaffer AA: Faster linkage analysis computations for pedigrees with loops or unused alleles. Hum Hered 1996; 46: 226-235.

27 Abecasis GR, Cherny SS, Cookson WO, Cardon LR: GRR: graphical representation of relationship errors. Bioinformatics 2001; 17: 742-743.

28 Abecasis GR, Cherny SS, Cookson WO, Cardon LR: Merlin - rapid analysis of dense genetic maps using sparse gene flow trees. Nat Genet 2002; 30: 97-101.

29 Kong A, Gudbjartsson DF, Sainz J et al: A high-resolution recombination map of the human genome. Nat Genet 2002; 31: $241-247$.
30 Broman KW, Murray JC, Sheffield VC, White RL, Weber JL: Comprehensive human genetic maps: individual and sex-specific variation in recombination. Am J Hum Genet 1998; 63: 861-869.

31 Fredriks AM, van Buuren S, Burgmeijer RJ et al: Continuing positive secular growth change in The Netherlands 1955-1997. Pediatr Res 2000; 47: 316-323.

32 Neale MC, Boker S, Xie G, Maes H: Mx: Statistical Modeling, Box 126 MCV, Richmond, VA 23298: Department of Psychiatry. 5th edition: 1999.

33 Sham P: Statistics in Human Genetics. London: Arnold Publishers, 1998.

34 Roberts SB, MacLean CJ, Neale MC, Eaves LJ, Kendler KS: Replication of linkage studies of complex traits: an examination of variation in location estimates. Am J Hum Genet 1999; 65: 876-884

35 Altmüller J, Palmer LJ, Fischer G, Scherb H, Wjst M: Genomewide scans of complex human diseases: true linkage is hard to find. $A m$ J Hum Genet 2001; 69: 936-950.

36 Ginsburg E, Livshits G, Yakovenko K, Kobyliansky E: Major gene control of human body height, weight and BMI in five ethnically different populations. Ann Hum Genet 1998; 62 (Part 4): 307-322. 